\title{
Conducting Metallopolymers Based on Azaferrocene
}

\author{
Paul D. Byrne, Peter Müller, Timothy M. Swager
}

Table 1. Crystal data and structure refinement for $\underline{1 a}$.

Identification code

05235

Empirical formula

$\mathrm{C}_{30.50} \mathrm{H}_{28} \mathrm{ClFeNS}_{4}$

Formula weight

628.08

Temperature

100(2) K

Wavelength

$0.71073 \AA$

Crystal system

Monoclinic

Space group

Pc

Unit cell dimensions

$\mathrm{a}=18.0259(17) \AA$

$\alpha=90^{\circ}$.

$b=14.9021(13) \AA$

$\beta=97.917(3)^{\circ}$.

$c=10.5521(8) \AA$

$\gamma=90^{\circ}$.

Volume

2807.5(4) $\AA^{3}$

Z

4

Density (calculated)

$1.486 \mathrm{Mg} / \mathrm{m}^{3}$

Absorption coefficient

$0.952 \mathrm{~mm}^{-1}$

$F(000)$

1300

Crystal size

$0.50 \times 0.45 \times 0.01 \mathrm{~mm}^{3}$

Theta range for data collection

1.14 to $30.73^{\circ}$.

Index ranges

$-25 \leq h \leq 25,0 \leq k \leq 21,0 \leq l \leq 15$

Reflections collected

10158

Independent reflections

$10158\left[R_{\text {int }}=\right.$ non-merohedral twin $]$

Completeness to theta $=30.73^{\circ}$

Absorption correction

$96.9 \%$

Max. and min. transmission

Semi-empirical from equivalents

0.9905 and 0.6474

Refinement method

Full-matrix least-squares on $F^{2}$

Data / restraints / parameters

10158 / 1148 / 761

Goodness-of-fit on $F^{2}$

1.016

Final $R$ indices $[I>2 \sigma(I)]$

$R 1=0.0539, w R 2=0.1136$ 
$R$ indices (all data)

Absolute structure parameter

Largest diff. peak and hole
$R 1=0.0703, w R 2=0.1188$

$0.12(2)$

0.854 and -0.874 e. $\AA^{-3}$

\section{X-ray Structural Studies}

Low temperature diffraction data were collected on a Siemens Platform three-circle diffractometer coupled to a Bruker-AXS Smart Apex CCD detector with graphitemonochromated MoK $\alpha$ radiation $(\lambda=0.71073 \AA)$, performing $\phi$ - and $\omega$-scans. The structure was solved by direct methods using SHELXS ${ }^{1}$ and refined against $F^{2}$ on all data by full-matrix least

squares with SHELXL-97. ${ }^{2}$ All non-hydrogen atoms were refined anisotropically. All hydrogen atoms were included into the model at geometrically calculated positions and refined using a riding model. The isotropic displacement parameters of all hydrogen atoms were fixed to 1.2 times the $U$ value of the atoms they are linked to (1.5 times for methyl groups). Crystal and structural refinement data are listed in Table 1.

The crystals were very thin, virtually two-dimensional, which gave rise to relatively anisotropic data. The crystal was non-merohedrally twinned. Two independent orientation matrices for the unit cell were found using the program CELL_NOW ${ }^{3}$, and data reduction taking into account the twinning was performed with $\mathrm{SAINT}^{4}$. The program twinabs ${ }^{5}$ was used to perform absorption correction and to set up the HKLF5 format file for structure refinement.

Each asymmetric unit contains two molecules of $\mathrm{C}_{30} \mathrm{H}_{27} \mathrm{FeNS}_{4}$ plus one molecule of $\mathrm{CH}_{2} \mathrm{Cl}_{2}$. As the number of molecules per unit cell is 4 , the resulting empirical formula as given in Table 1 has a non-integer number of carbon atoms, corresponding to one half solvent molecule crystallized per target molecule. Two of the four crystallographically independent thiophene ligands show disorder corresponding to a rotation about the $\mathrm{C}-\mathrm{C}$ single bond between the two five membered rings. These disorders were refined with the help of similarity restraints on 1-2 and 1-3 distances and displacement parameters as well as rigid bond restraints for anisotropic displacement parameters and planarity restraints for the atoms involved. The relative 
occupancies of the disordered components were refined freely, while constraining the total occupancy of both components to unity.

The Flack- $x$ parameter ${ }^{6}$ refined to $0.12(2)$. This means that the crystal is probably also a racemic twin, but the TWIN instruction is not compatible with the HKLF5 format required for non-merohedral twins. Therefore the racemic twinning was ignored. This still results in a good and accurate structure, as the twin ratio is likely to be close to 0.1 (as estimated from the value of the Flack- $x$ parameter), which is not a very high value for a twin ratio.

\section{XPS Survey Scan of p-1c}

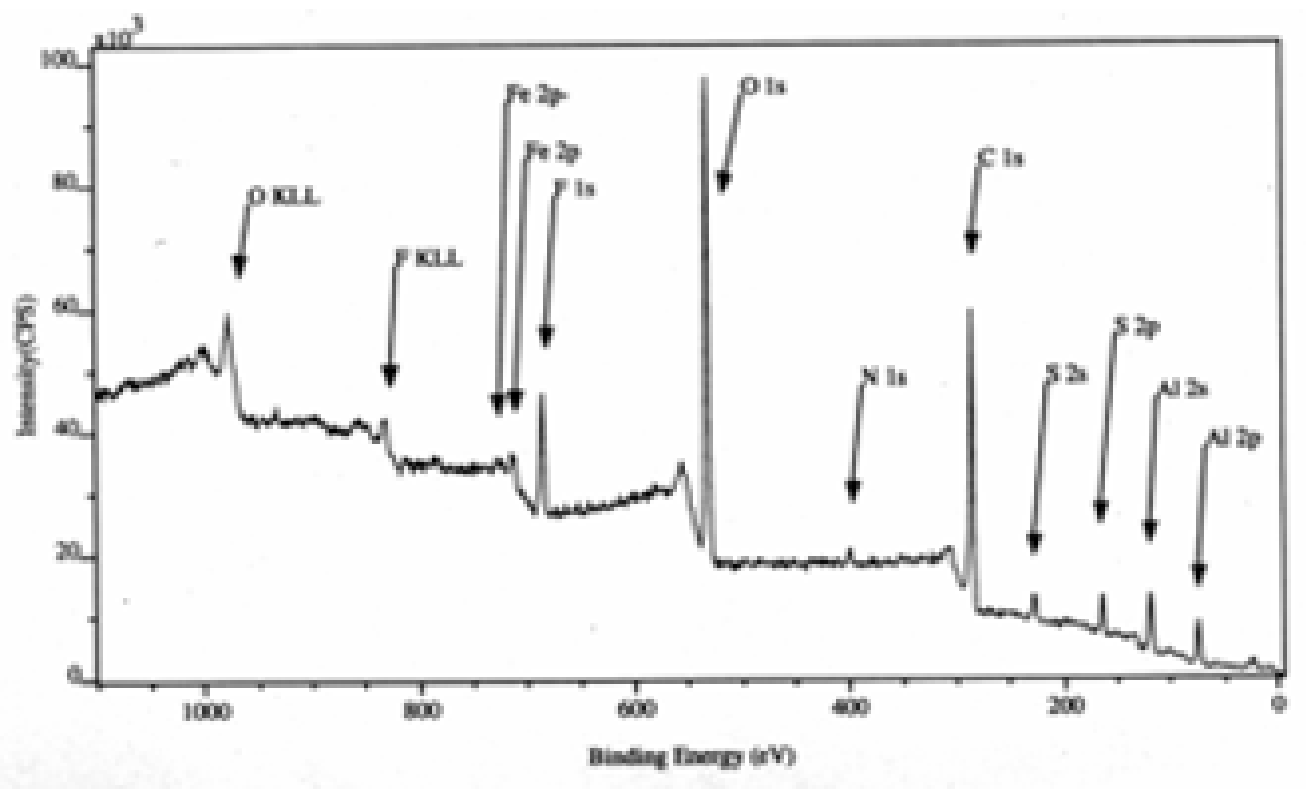

\section{References}

${ }^{1}$ Sheldrick, G. M. Acta Cryst. 1990, A46, 467.

${ }^{2}$ Sheldrick, G. M (1997). SHELXL 97, University of Göttingen, Germany.

${ }^{3}$ Sheldrick, G. M (2003). CELL_NOW, University of Göttingen, Germany. 
${ }^{4}$ Bruker (2005). SAINT, Bruker-AXS Inc., Madison, Wisconsin, USA.

${ }^{5}$ Sheldrick, G. M (2002). twinabs, University of Göttingen, Germany.

${ }^{6}$ Flack, H. D. Acta Cryst. 1983, A39, 876. 